\title{
Mechanisms of eosinophil cytokine release
}

\author{
Christianne Bandeira-Melo/ ${ }^{++}$, Peter F Weller*/+
}

\begin{abstract}
Laboratório de Imunofarmacologia, Departamento de Fisiologia e Farmacodinâmica, Instituto Oswaldo Cruz-Fiocruz, Rio de Janeiro, RJ, Brasil *Department of Medicine, Harvard Thorndike Laboratories, Charles A. Dana Research Institute, Beth Israel Deaconess Medical Center, DA - 617, 330 Brooklyne Avenue, Harvard Medical School, Boston, MA, 02215, US
\end{abstract}

Human eosinophils have been demonstrated to contain a multitude of cytokines and chemokines that exist preformed within these cells. This content of pre-formed cytokines, with diverse potential biologic activities, provides eosinophils with capabilities distinct from most other leukocytes. The localization of pre-formed cytokines within eosinophils is both within specific granules and associated with substantial numbers of morphologically distinct cytoplasmic vesicles. Stimulation for release of specific cytokines, such as IL-4, leads to a regulated signal transduction cascade, which is dependent on the formation of leukotriene $C_{4}$ within eosinophils where it acts as an intracrine mediator. IL-4 release occurs selectively and is by means of vesicular transport. The capabilities of eosinophils not only to rapidly release pre-formed cytokines but also to differentially regulate which cytokines are released endow eosinophils with distinct abilities in innate and acquired immunity.

Key words: eosinophils - cytokines - degranulation

\section{Background}

Eosinophil specific granules contain four distinct cationic proteins, named major basic protein (MBP), eosinophil peroxidase (EPO), eosinophil cationic protein (ECP) and eosinophil-derived neurotoxin (EDN), whose extracellular release may cause dysfunction and destruction of surrounding cells (reviewed Gleich et al. 1992). In addition to these toxic proteins, eosinophil specific granules also store at least two-dozen of pre-formed cytokines and chemokines with pro-inflammatory or immunoregulatory properties. By a variety of techniques, such as subcellular fractionation, immunogold electron microscopy, and immunocytochemistry, a growing list of cytokines has been found within human eosinophil granules, including: (a) prototypical Th1 cytokines: IL-12 (Grewe et al. 1998) and IFN- $\gamma$ (Lamkhioued et al. 1996); (b) prototypical Th2 cytokines: IL-4 (Moller et al. 1996b), IL-5 (Dubucquoi et al. 1994, Moller et al. 1996a, Desreumaux et al. 1998) and IL-13 (Woerly et al. 2002); (c) chemokines: RANTES (Lim et al. 1996, Ying et al. 1996), IL-8 (Braun et al. 1993), and eotaxin (Nakajima et al. 1998); (d) growth factors: granulocyte/macrophage colony-stimulatin factor (GM-CSF) (Levi-Schaffer et al. 1995, Desreumaux et al. 1998), IL-3 (Desreumaux et al. 1998), vascular endothelial growth factor (VEGF) (Horiuchi \& Weller 1997), transforming growth factor (TGF)- $\alpha$ (Egesten et al. 1996) and stem cell factor (SCF) (Hartman et al. 2001); (e) pro-inflammatory cytokines: tumor necrosis factor (TNF)- $\alpha$ (Beil et al. 1993) and IL-6

Financial support: NIH grants (AI20241, AI22571, and HL56386), CNPq, Faperj

${ }^{+}$Corresponding author. E-mail: pweller@ caregroup.harvard.edu

${ }^{++}$Profix fellowship from CNPq

Received 8 November 2004

Accepted 30 December 2004
(Lacy et al. 1998); and (f) immune-regulators: IL-16 (Lim et al. 1996), IL-2, and IL-10 (Woerly et al. 1999).

In view of such diverse functional potentiality, eosinophil degranulation is a critical process by which eosinophils may damage, activate or down-regulate the neighboring cells. Hence, it was hypothesized that not all granule proteins are concomitantly released from eosinophils. Conversely, a regulated mechanism to specifically select and release proteins from eosinophil granules may exist. Ultrastructural observations, made in the beginning of the 1990s, strongly support such hypothesis (vide infra; (Dvorak et al. 1991, 1992). However, it was only during the last decade that the question of "how distinct cytokines, packed together within specific granules, are differentially released by eosinophils?" started to be addressed systematically. In this review, we considered the evolving understanding of the mechanisms of eosinophil degranulation, focusing on the critical role of the vesicular transport, as well as, the intracrine regulation by cysteinyl leukotrienes.

\section{How do eosinophils release stored proteins?}

In human eosinophils, the secretion of cytokines may occur via different pathways (Fig. 1). Eosinophils can release newly synthesized cytokines by the constitutive pathway; a process readily blocked by inhibitors of protein synthesis such as actinomycin D or cycloheximide (Fig. 1; top panel). Release of newly formed cytokines is dependent on vesicular transport, both at the ER/Golgi compartments and between the Golgi and the cytoplasmic membrane. Therefore, brefeldin A and monensin drugs that by distinct mechanisms inhibit vesicle formation - also can disrupt this kind of cytokine release. Eosinophils may take hours to synthesize and release newly formed cytokines after a specific stimulation (e.g. fibronectin-induced GM-CSF release by eosinophils); (Anwar et al. 1993, Meerschaert et al. 1999), but the constitutive pathway is typical of lymphocytes, and does not represent the main form of eosinophil cytokine secretion. 


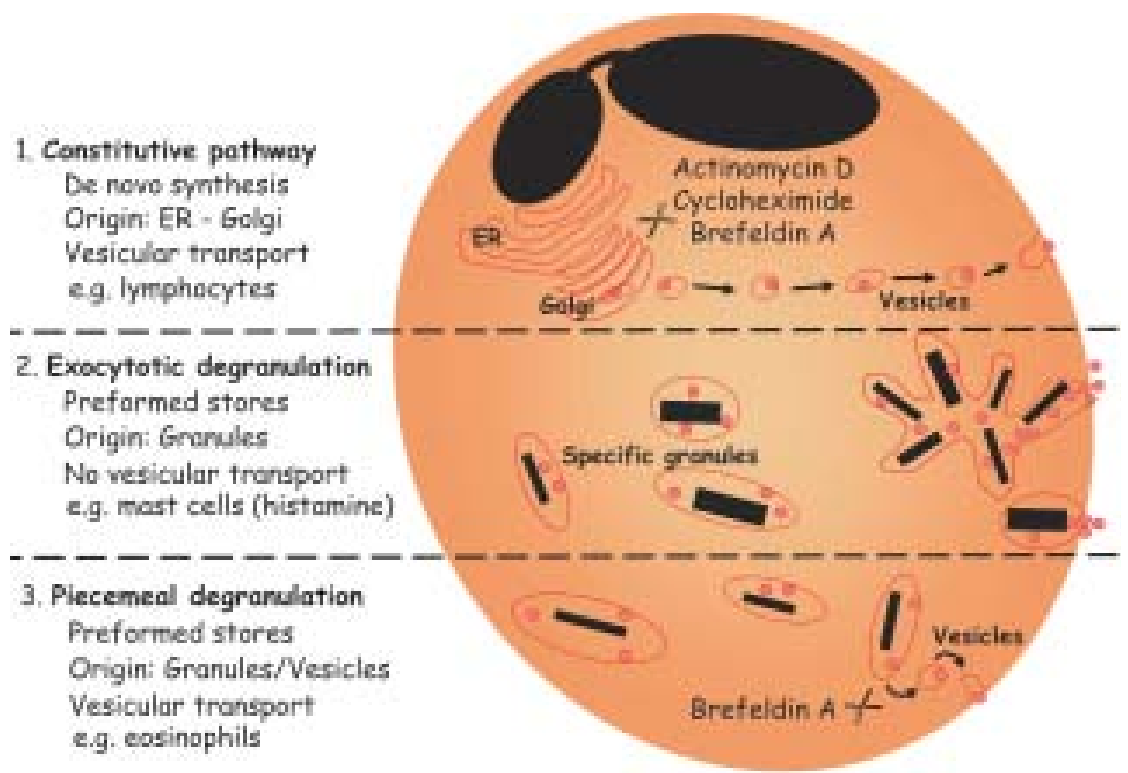

Fig. 1: eosinophil pathways of cytokine secretion

Inasmuch as eosinophils store pre-formed cytokines within their specific granules, they can release cytokines without employing a lengthy process of de novo synthesis. In particular conditions, eosinophils appear to undergo a process of "exocytotic degranulation" (e.g. against parasites); (Scepek et al. 1994). This secretory pathway allows, for instance, the release of granule-derived toxic proteins onto helminth surfaces by eosinophils, but does not enable them to differentially release their granulestored cytokines. By exocytosis, eosinophils discharge their entire granule content by directly fusing the granular membrane (of a single granule or multiple fused granules) to the cytoplasmic membrane (Fig. 1; middle panel). Exocytic degranulation is an acute event that does not depend on protein synthesis or vesicular transport. Pharmacological maneuvers to disrupt such potentially damaging process were not yet identified. Under appropriate stimulation, mast cells can professionally perform exocytosis (Hide et al. 1993), while eosinophils appear to master another kind of degranulation.

By analyzing ultrastructural images of tissue samples, Dvorak et al. (1991) identified a new secretory pathway by which the eosinophil granule proteins are mobilized and released by a mechanism that: (i) does not involve the wholesale secretion of granule content like in exocytosis; (ii) leaves behind partially empty membrane-bound granule chambers; and (iii) depends on the trafficking of small vesicles. This vesicular transport-based process, named "piecemeal degranulation", enables eosinophils to perform the differential release of granule-derived cytokines (Fig. 1; bottom panel). Therefore, drugs that control vesicle formation (e.g. brefeldin A), trafficking (e.g. inhibitors of myosin), or docking/fusion (e.g. tetanus and botulinum neurotoxins) to plasma membrane, should block eosinophil piecemeal degranulation. Although it is not clear how vesicles are loaded with eosinophil granule contents, at least two distinct mechanisms have been suggested: docking/fusion of pre-existing cytoplasmic vesicles to eosinophil granules (Logan et al. 2003) or "budding" of new vesicles from eosinophil granule membranes (Feng et al. 2001). Piecemeal degranulation appears to be the major secretory pathway of eosinophils. There is in vivo evidence that murine eosinophils can rapidly (within minutes) release IL-4 to initiate a Th2 response to Schistosoma mansoni infection (Sabin \& Pearce 1995, Sabin et al. 1996). Nevertheless, piecemeal degranulation is not restricted to eosinophils, since it is also exhibited by other leukocytes such as professional exocytotic mast cells (Crivellato et al. 2002).

Recently, laboratories around the world have achieved considerable advances unveiling key features of eosinophil piecemeal degranulation (for review see Logan et al. 2003). By using different technical strategies, including immunogold analysis, ELISA, subcellular fractionation, two-color confocal microscopy and EliCell, the path of granule-derived cytokines to the extracellular compartment of properly stimulated eosinophils was tracked. For instance, Lacy et al. (1999) reported that RANTES may be rapidly mobilized and selectively released from eosinophils by piecemeal degranulation upon IFN- $\gamma$ stimulation (Lacy et al. 2001), since vesicles transported it for release by a mechanism controlled by the vesicle-associated membrane protein-2 (VAMP-2), a member of SNARE (Nethylmaleimide-sensitive factor attachment protein receptor) family, which is a key molecule to vesicle docking/ fusion with membranes. Selective release for eosinophil granule-derived cytokines was also observed by Woerly et al. $(1999,2002)$. They demonstrated that cross-linking of surface CD28 induces release of biologically active IL2 , IFN- $\gamma$ and IL-13, whereas plate-bound secretory IgA complexes induce release of IL-10 from eosinophils.

To study eosinophil degranulation, we have developed a new methodology that better suits the evaluation of the mechanisms of eosinophil degranulation based on 
vesicular mobilization and transport of granule contents. The available methods did not appear proper to access all the complex features of eosinophil piecemeal degranulation, since: (a) vesicular transport will mobilize selected granule proteins and release them progressively in small packets in the microenvironment around the eosinophil, that may not be readily detectable in fluid phase assays of supernatants by ELISA, especially early in the release process, because overall levels in the supernatant fluids are too low for assay and/or because some proteins remain bound to eosinophils (as shown for EPO); (b) tissue eosinophils are adherent cells that interact with elements of the extracellular matrix, to recapitulate responses of tissue eosinophils, would be advantageous to study eosinophils in an appropriate gel-phase matrix; and (c) conventional ELISPOT assays routinely permeabilize cultured cells, such as lymphocytes, to detect newly formed cytokines or immunoglobulins (King et al. 1990), these assays are not suitable for eosinophils, which contain preformed cytokines and other granule proteins. Thus, to detect only extracellularly released proteins by immunostaining, eosinophils must remain viable and impermeant to detecting antibodies. Altogether, the study of eosinophil vesicular transport as a means to mobilize preformed eosinophil granule cytokines and other proteins required new experimental assays. The new methodology, that we developed, sensitively evaluates extracellular release of eosinophil granule-derived cytokines. The EliCell is a microscopic dual-antibody capture and detection system in which viable eosinophils are incubated in a gel matrix (Bandeira-Melo et al. 2000, 2003).

Our group, by employing the EliCell technique, has identified physiological stimuli that trigger piecemeal degranulation by eosinophils:

1 - Physiological stimulation of eosinophils by the CC chemokines eotaxin or RANTES induces IL-4 release by a non-cytotoxic mechanism (Bandeira-Melo et al. 2001b). Of note, the CXC chemokine IL- 8 or the Th1 cytokine IFN- $\gamma$ did not elicit IL-4 release, suggesting that distinct signaling cascades may function to selectively mobilize at least the cytokine proteins stored preformed in eosinophil granules. Eotaxin-induced IL-4 release was potentiated by IL- 5 and mediated by G protein-coupled CCR3 receptors. It was also a very rapid phenomenon, apparent within $5 \mathrm{~min}$, and not diminished by transcription or protein synthesis inhibitors (actinomycin D and cycloheximide), confirming that the IL-4 detected extracellularly was not released by the constitutive pathway. Consistent with piecemeal degranulation, eotaxin-induced IL-4 release was suppressed by brefeldin A, an inhibitor of vesicle formation. Therefore, we concluded that CCR3-mediated signaling can rapidly mobilize IL-4 stored pre-formed within human eosinophils for release by piecemeal degranulation;

2- IL-16 induces IL-4 release through the eotaxin/ RANTES-driven signaling pathway described above (Bandeira-Melo et al. 2002). IL-16, a recognized eosinophil chemoattractant (Rand et al. 1991), dose dependently (0.01-100 nM) elicited a brefeldin A-inhibitable, vesicular transport-mediated release of pre-formed IL-4 from eosinophils. Treatments with anti-CD4 Fab, soluble CD4, or a
CD4 domain 4-based IL-16 blocking peptide inhibited IL16-induced IL-4 release by eosinophils, indicating that IL-16 induces piecemeal degranulation via its recognized receptor CD4. Although CD4 is not a G-protein coupled receptor, pertussis toxin inhibited IL-16-induced eosinophil activation. IL-16 actions were found to be mediated by an autocrine activity of endogenous CCR3-acting chemokines. In fact, IL-16 induced the rapid vesicular transport-mediated release of RANTES, which preceded IL-4 release. The effects of IL-16 were blocked by CCR3 inhibitors (met-RANTES, anti-CCR3 mAb) and by neutralizing anti-eotaxin and anti-RANTES monoclonal antibodies. Therefore, IL-16 activates CD4 molecules expressed on eosinophil surface to elicit very rapid piecemeal degranulation of RANTES and eotaxin, which then in an autocrine fashion act on plasma membrane CCR3 receptors to stimulate vesicular transport-mediated release of IL-4 from eosinophils;

3 - Stimulation of eosinophils through the surface molecules CD9 or LIR7 triggered release of IL-12 (Tedla et al. 2003). Stimulation through CD9 or LIR7 was detectable by 15 and $60 \mathrm{~min}$, respectively. The rapid release of IL-12 in response to engagement of LIR7 or CD9 suggested the release of pre-formed cytokines by a process of vesicular transport. Consistent with this mechanism, pre-treatment of eosinophils with cycloheximide did not inhibit IL-12 release in response to CD9 or LIR7 cross-linking, indicating that IL-12 was pre-formed rather than generated de novo. In contrast, release of IL-12 after engagement of LIR7 or CD9 was blocked by pre-treatment of the cells with brefeldin $\mathrm{A}$, which disrupts the formation of vesicles. Therefore, piecemeal degranulation is also the secretory pathway involved in IL-12 released triggered by the crosslinking of CD9 or LIR7.

In vitro, non-physiological stimulation of eosinophils with either serum-coated beads, IgA immune-complexes, or calcium ionophore A23187 (Moqbel et al. 1995, Nonaka et al. 1995, Bjerke et al. 1996) can lead to non-selective secretory processes that may be exocytotic and/or cytolytic (Fukuda et al. 1985, Weiler et al. 1996). By using the EliCell assay, we confirmed that the calcium ionophore A23187 stimulated the release of both IL-12 and IL-4, detectable extracellularly around eosinophils exhibiting morphological signs of exocytotic/cytolytic process and cell damage (Bandeira-Melo et al. 2001b, Tedla et al. 2003). Consistently, brefeldin A had no effect on the release of IL-4 or IL-12 from A23187-stimulated eosinophils. Cytolysis is a process related to cell death (also called "necrosis") by which cell membrane (and sometimes organelle membrane) is ruptured and specific eosinophil granules are liberated into the surrounding tissue. Of note, there are some reports showing that, in human diseases, intact membrane-bound eosinophil granules accumulate into tissues while granule-derived toxins distribute in the eosinophil cytoplasm as granules disintegrate during cell disruption (Gleich et al. 1984, Davis et al. 1998, Erjefalt et al. 1999), indicating that besides piecemeal degranulation, eosinophils can undergo "cytolysis". Whether the mechanisms involved in generating cytolytic eosinophils in vivo are accidental or regulated need to be investigated.

Altogether, these findings demonstrated that piece- 
meal degranulation by eosinophils is a very rapid, but highly regulated vesicular process. In addition they support the concept of stimulus-dependent release of eosinophil pre-formed cytokines.

\section{Are pre-formed IL-4 and IL-12, cytokines with opposing} functions, released alongside by eosinophils?

Conceptually, differential release is a possible outcome of piecemeal degranulation by which granule-derived toxins versus cytokines or cytokines with opposing functions are not secreted alongside. In practice, differential release of eosinophil granule content was first indicated by ultrastructural analysis of in vitro differentiated-eosinophils showing within the cytosol some membranebound semi-emptied granule chambers, free of matrix proteins (e.g. EPO), but with residual crystalloid core (Dvorak et al. 1992). Differential release of eosinophil granule-derived proteins requires a refined system of picking specific cytokines stored together within eosinophil granules to be packed into transporting vesicles. Although the mechanisms involved in choosing specific proteins at the interface between granule and vesicle are still not well defined, few features of this process have been recognized, including its high speed, pre-existence of regulatory proteins (no need of new synthesis) and stimulus specificity.

We have also confirmed the hypothesis that the vesicular transport-mediated process of eosinophil degranulation can be highly selective. For instance, the IL-16initiated transport of RANTES occurred in vesicles that were not loaded with IL-4. RANTES release preceded release of IL-4, which only later was packed in vesicles formed in response to the CCR3-active chemokines (Bandeira-Melo et al. 2002). Additional selectivity in the regulated release of eosinophil-derived cytokines was evident in the release of IL-4, but not of IL-12, by the IL16- or CCR3 chemokine-activated eosinophils (BandeiraMelo et al. 2002, Tedla et al. 2003). Moreover, the crosslinking of eosinophil surface molecules CD9 or LIR7 triggered differential release of IL-12, but not IL-4, by a process of piecemeal degranulation, by which transporting vesicles selectively secreted IL-12 (Tedla et al. 2003). These results are summarized in Fig. 2 and indicate that eosinophil granule-derived IL-4 and IL-12 may have mutual exclusive mechanisms of vesicle secretion. Inasmuch as IL-4 favors the development of Th2 responses, whereas IL-12 favors the development of Th1 responses (Romagnani 1997) the selective release of IL-4 in response to eotaxin is consistent with the proposed role of that chemokine in Th2-dependent eosinophilic inflammation (Rothenberg et al. 1999). On the other hand, the specific release of IL-12, but not IL-4, from eosinophils in response to engagement of CD9 or LIR7 suggests a possible function for these orphan receptors in tempering Th2 cell-dependent inflammatory responses and indicates that the counter-regulatory function of the LIRs may not be confined to the inhibitory members of this family of receptors (e.g. inhibitory LIR3 also expressed on eosinophil membrane; Tedla et al. 2003).

Other examples of differential release of specific

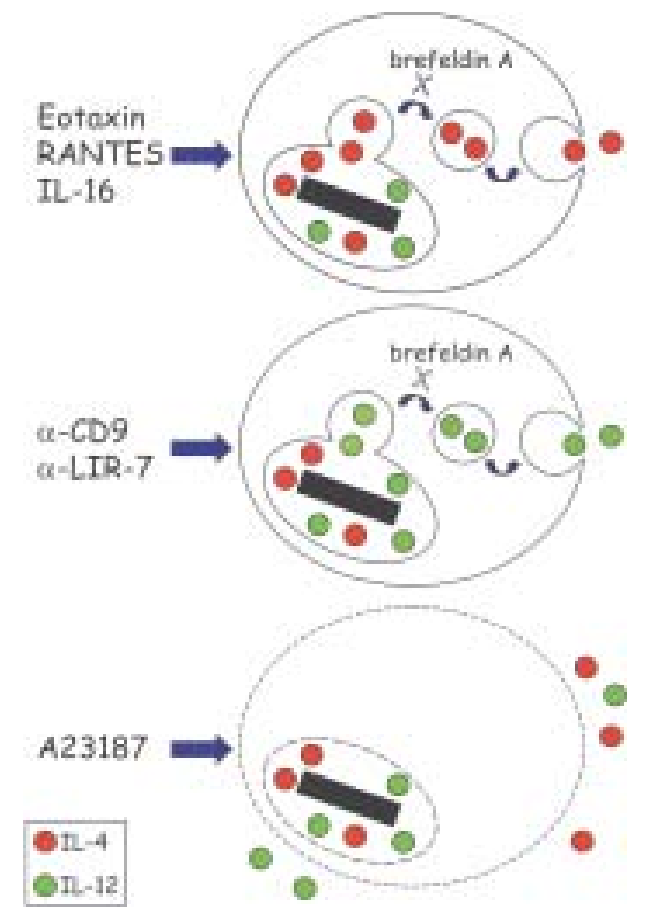

Fig. 2: differential release of eosinophil cytokines.

cytokines from eosinophils by piecemeal degranulation triggered by distinct stimulatory conditions are: (a) rapid vesicle-mediated release of RANTES elicited by IFN- $\gamma$ stimulation, which fails to induce concomitant release of MBP (Lacy et al. 1999) or IL-4 (Bandeira-Melo et al. 2001b); (b) release of biologically active Th1 cytokines IFN- $\gamma$ and IL-2 (Woerly et al. 1999), as well as, the pro-inflammatory cytokine IL-6 (Woerly et al. 2004) induced by cross-linking eosinophil surface CD28, that does not trigger parallel release of IL-10; (c) release of IL-10 and IL-6 induced by IgA immune-complexes, that fails to trigger IFN- $\gamma$ and IL2 release (Woerly et al. 1999, 2004); and (d) release of biologically active IL-13 induced by cross-linking eosinophil surface $\mathrm{CD} 28$, that does not trigger IL-10 release (Woerly et al. 2002).

Additional evidence of differential release of eosinophil granule-derived cytokines came from a pharmacological study investigating potential direct effects of the anti-allergic drug suplatast tosilate on eosinophil activation (Woerly et al. 2004). Upon activation by cross-linking CD28 expressed on eosinophil membrane, the release of the Th2 cytokine IL-13 from eosinophils was inhibited by the treatment with suplatast tosilate, whereas release of IL- 2 and IFN- $\gamma$ was not affected. These data indicate that even though the release of IL-13 versus the Th1 cytokines is triggered by the same stimuli, distinct intracellular mechanisms control their piecemeal degranulation.

\section{How does lipid body-derived $\mathrm{LTC}_{4}$ control eosinophil cytokine release?}

The yet poorly understood mechanism of piecemeal degranulation of cytokines by eosinophils is a highly regu- 
lated phenomenon that involves a cascade of intracellular events. Specific receptor-driven downstream signaling appears to rapidly define which granular proteins will be selectively loaded within secretory vesicles. What signaling molecules control such sophisticated process? Several molecules have been identified as critical to vesicle budding, trafficking and docking, including membraneassociated proteins known as SNAREs, syntaxin-binding proteins (Sec1/Munc18), protein kinases (PKCs) and Rab GTPases (for complete review see Logan et al. 2003). Naturally, other molecules should be involved in such complex phenomenon and need to be characterized.

We have investigated the role of the endogenous leukotriene $(\mathrm{LT}) \mathrm{C}_{4}$ in piecemeal degranulation by eosinophils. Eosinophils are a major source of $\mathrm{LTC}_{4}-$ the principal product of the 5-lipoxygenase (5-LO) pathway of arachidonic acid metabolism in these cells (Weller et al. 1983) - which with its extracellular derivatives $\mathrm{LTD}_{4}$ and $\mathrm{LTE}_{4}$ play key roles in the pathogenesis of asthma and other allergic inflammatory diseases (Christie \& Henderson 2002). As illustrated in Fig. 3, distinct receptor-initiated signaling pathways that elicit the vesicular transport-mediated release of the pre-formed cytokines IL-4 or IL-12, also induce LTC $_{4}$ production by eosinophils. Interestingly, we have noticed that depending on the stimulus, the localized synthesis of LTC $_{4}$ may take place at distinct intracellular sites within eosinophils and may control the role of this mediator as either an intracrine signal-transducing mediator that regulate piecemeal degranulation, or as an autocrine/paracrine agent in allergic inflammation (for review see (Bandeira-Melo \& Weller 2003). Specifically, we verified that eosinophil stimulation with IL-16 and CCR3-activating chemokines elicited LTC $_{4}$ production within lipid bodies (Bandeira-Melo et al. 2001a, b) - cytoplasmic organelles rich in lipids, whose formation is highly regulated and have functions in eicosanoid production and storage of inflammatory proteins (vide infra; for review see Bozza \& Bandeira-Melo chapter in this same issue). Distinctly, cross-linking of CD9 and LIR7 induce $\mathrm{LTC}_{4}$ synthesis at the eosinophil perinuclear membrane (Tedla et al. 2003).

A further distinguishing feature of IL-4 versus IL-12 piecemeal release from eosinophils is the regulation by endogenous 5-LO metabolites. While IL-4 release induced by IL-16 and CCR3-activating chemokines is dependent on the formation of new 5-LO pathway-derived eicosanoids, IL-12 released induced by cross-linking of CD9 or LIR7 does not appear to be regulated by a 5-LO metabolite (Fig. 3). Pre-treatment with two mechanistically distinct inhibitors of 5-LO (AA861 and MK886) blocked IL-16-, eotaxin-, and RANTES-induced LTC $_{4}$ production and IL-4 release from eosinophils. In contrast, pre-treatment of eosinophils with either AA861 or MK886, that as expected impaired $\mathrm{LTC}_{4}$ production at eosinophil perinuclear membrane, did not inhibit the selective release of IL-12 induced by the cross-linking of CD9 or LIR7 (unpublished data). Thus, eosinophil-derived 5-LO metabolites mediate CCR3 chemokine-initiated signaling to release IL-4, but do not participate in CD9- or LIR7-driven selective IL-12 release.
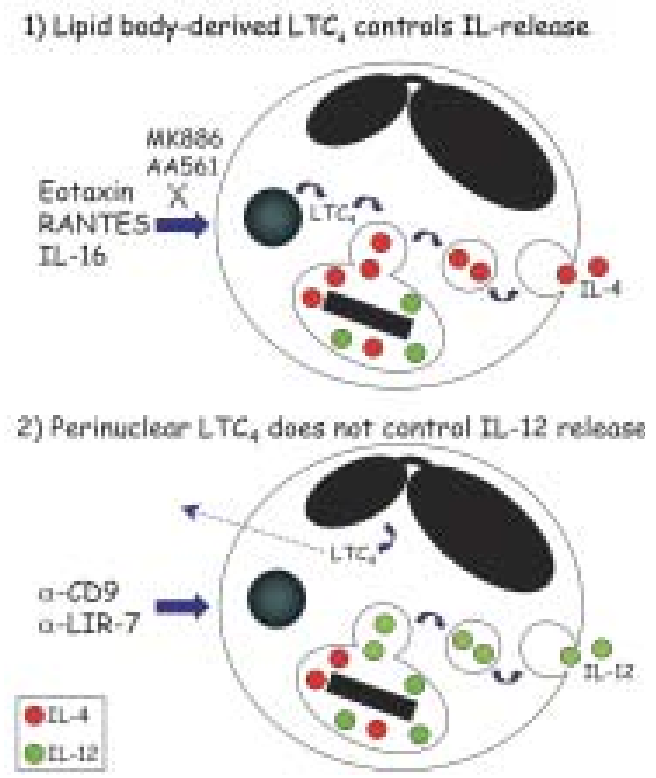

Fig. 3: LTC $_{4}$-driven cytokine differential release depends on LTC $_{4}$ site of synthesis.

To verify whether the 5-LO-derived eicosanoid, generated in response to CCR3 activation and involved in IL4 secretion from eosinophils, corresponded to endogenously synthesized LTC $_{4}$ (Bandeira-Melo et al. 2002), we have directly stimulated eosinophils with exogenous $\mathrm{LTC}_{4}$. Because $\mathrm{LTC}_{4}$ is synthesized intracellularly at cytoplasmic lipid bodies within IL-16-, eotaxin-, or RANTESstimulated eosinophils and is not permeable across the plasma membrane, we investigated whether $\mathrm{LTC}_{4}$ acting intracellularly could trigger IL-4 release. To investigate such potential intracrine signaling, we permeabilized eosinophils in order to allow impermeable $\mathrm{LTC}_{4}$ to enter eosinophils. LTC $_{4}$ induced IL-4 release from permeabilized eosinophils, but not from intact eosinophils. Moreover, stimulation of permeabilized eosinophils with $\mathrm{LTC}_{4}$ did not elicit IL-12 release. Like in IL-16-, eotaxin-, and RANTES-stimulated eosinophils, LTC $_{4}$-induced IL-4 release from permeabilized eosinophils was morphologically consistent with vesicular transport and significantly inhibited by brefeldin A, indicating that a vesicular transport-mediated process was also responsible for $\mathrm{LTC}_{4}$-elicited selective secretion of IL-4.

Overall, intracellular 5-LO-derived $\mathrm{LTC}_{4}$ formed at lipid bodies appears to function as an intracrine, and not extracellular autocrine/paracrine, mediator to regulate the differential secretion of IL-4 induced by IL-16, eotaxin, or RANTES. On the other hand, intracellular 5-LO-derived $\mathrm{LTC}_{4}$ formed at perinuclear membrane appears not control the selective IL-12 release induced by the cross-linking of CD9 or LIR7, and may function as a autocrine/ paracrine mediator of inflammation. The capacity of eosinophils to synthesize LTC $_{4}$ at two distinct compartments, nuclear envelopes and/or lipid bodies, raises still unanswered questions about LTC $_{4}$ roles in eosinophil activation. Our study started to uncover some of these roles, demonstrating that some of the specificity in secreting 
selective cytokines from eosinophils is based on the activation of intracellular lipid body-derived $\mathrm{LTC}_{4}$ signaltransducing pathways.

\section{Are pre-formed cytokines stored within other eosinophil intracellular compartments?}

In human eosinophils, pre-formed cytokines appeared to be stored in at least two distinct intracellular compartments other than eosinophil specific granules. Eosinophils have a distinctive vesicular compartment that appear to stock pre-formed cytokines. Lacy et al. (1999) showed the existence of an extragranular pool of preformed RANTES stored within small secretory vesicles. Using an elegant approach, they showed that the release of vesicle-stored RANTES preceded the piecemeal degranulation of granule-stored RANTES after IFN- $\gamma$ stimulation, indicating that eosinophils have a complementary vesicle-mediated mechanism for rapid release of extragranular stored cytokines.

A third intracellular compartment of cytokine storage within eosinophils is the cytoplasmic lipid body. As mentioned before, lipid bodies are lipid rich organelles that have roles on eicosanoid synthesis. But relevant to other lipid body functions is the knowledge that leukocyte lipid bodies contain several functionally diverse types of proteins, including structural proteins (e.g. the PAT proteins perilipin, ADRP and TIP47), eicosanoid-forming enzymes (such as cPLA2, 5-LO, 15-LO, COX and $\mathrm{LTC}_{4}$ synthase), kinases (e.g. the MAP kinases ERK1, ERK2, p85 and p38), metabolic enzymes, proteins of Rab family and small GTPases, and therefore lipid bodies besides regulating eicosanoid synthesis may control lipid metabolism, membrane trafficking and intracellular signaling (Dvorak et al. 1994, Bozza et al. 1997, 1998, Heid et al. 1998, Yu et al. 1998, Brasaemle et al. 2004, Fujimoto et al. 2004, Liu et al. 2004, Maya-Monteiro et al. unpublished data). Additional immunoregulatory functions can also be postulated to lipid bodies, since they also store growth factors, cytokines and chemokines. The first cytokine found within lipid bodies was tumor necrosis factor-alpha (TNF- $\alpha$ ). TNF- $\alpha$ was detected within cytoplasmic lipid bodies of several cell types present on colonic Crohn's disease biopsies, including infiltrating eosinophils (Beil et al. 1993). Recently, TNF- $\alpha$ was also found within lipid bodies of circulating neutrophils of septic patients and murine infiltrating neutrophils of experimentally induced sepsis (Pacheco et al. 2002). Cytoplasmic lipid bodies of isolated human lung mast cells contain the basic fibroblast growth factor (bFGF), also found within mast cell secretory granules (Dvorak et al. 2001). Specifically within eosinophils, the presence of TNF- $\alpha$ (Beil et al. 1993) and the lymphocyte chemoattractants RANTES and IL-16 (Lim et al. 1996) has been detected at lipid bodies. It is noteworthy that TNF- $\alpha$, RANTES and IL-16 are largely stored within eosinophil specific granules. If lipid bodies represent additional subcellular storage compartments for cytokines within eosinophils, alternative release routes for a cytokine distinct of vesicular transport-mediated secretion may exist. Of note, lipid bodies do not contain a typical membrane of phospholipid bilayer. Instead, they are surrounded by a monolayer of phospholipids and structural proteins
(Heid et al. 1998, Bandeira-Melo \& Weller 2003, MayaMonteiro et al. unpublished data), which may not allow that vesicles "bud from" or vesicles "dock to" lipid bodies. Therefore, cytokines stored within cytoplasmic lipid bodies may not be released from eosinophils by piecemeal release or not be released at all. Like lipid bodyderived $\mathrm{LTC}_{4}$, lipid body-stored cytokines may also function as intracrine signaling mediators.

\section{Concluding}

Eosinophils are prominent in Th2-driven immune responses, including asthma and allergic and parasitic diseases. As inflammatory cells, eosinophils contribute to the pathogenesis of allergic inflammation by secreting toxic granule proteins and lipid mediators. In addition to their roles in acute inflammation, eosinophils are now recognized as immuno-modulatory cells, since they have the ability to interact with T and B lymphocytes. Eosinophil/ lymphocyte interactions are achieved via direct stimulation by co-stimulatory surface proteins expressed on eosinophils (e.g. CD40, CD28, CD86 and MHC class II) (Weller et al. 1993, Ohkawara et al. 1996, Woerly et al. 1999), or via indirect stimulation by cytokines secreted by eosinophils. Interestingly, inasmuch as airway eosinophils can traffic back to regional lymph nodes and effectively present airway-derived antigens to elicit proliferation of $\mathrm{CD} 4^{+} \mathrm{T}$ cells (Shi et al. 2000), local release of IL-4 or IL-12 by eosinophils within lymph nodes, the thymus or other sites may also modulate the response type of lymphocytes. The appreciation of the vast cytokine biosynthetic, compartmentalizing and functional capacity of eosinophils identifies the mechanisms of cytokine secretion by eosinophils as a critical target for further studies. New therapeutic approaches for the treatment of eosinophil-related pathologies, including allergic diseases, could be aided by the development of agents that target specific eosinophil secretory pathways, such as piecemeal degranulation.

\section{ACKNOWLEDGEMENTS}

To Dr Bruno L Diaz for helpful discussion.

\section{REFERENCES}

Anwar AR, Moqbel R, Walsh GM, Kay AB, Wardlaw AJ 1993. Adhesion to fibronectin prolongs eosinophil survival. J Exp Med 177: 839-843.

Bandeira-Melo C, Weller PF 2003. Eosinophils and cysteinyl leukotrienes. Prostaglandins Leukot Essent Fatty Acids 69: 135-143.

Bandeira-Melo C, Gillard G, Ghiran I, Weller PF 2000. EliCell: a gel-phase dual antibody capture and detection assay to measure cytokine release from eosinophils. J Immunol Methods 244: 105-115.

Bandeira-Melo C, Perez SA, Melo RC, Ghiran I, Weller PF 2003. EliCell assay for the detection of released cytokines from eosinophils. J Immunol Methods 276: 227-237.

Bandeira-Melo C, Phoofolo M, Weller PF 2001a. Extranuclear lipid bodies, elicited by CCR3-mediated signaling pathways, are the sites of chemokine-enhanced leukotriene $\mathrm{C} 4$ production in eosinophils and basophils. J Biol Chem 276: 22779-22787. 
Bandeira-Melo C, Sugiyama K, Woods LJ, Phoofolo M, Center DM, Cruikshank WW, Weller PF 2002. IL-16 promotes leukotriene $\mathrm{C}(4)$ and IL-4 release from human eosinophils via CD4- and autocrine CCR3-chemokine-mediated signaling. J Immunol 168: 4756-4763.

Bandeira-Melo C, Sugiyama K, Woods LJ, Weller PF 2001b. Cutting edge: eotaxin elicits rapid vesicular transport-mediated release of preformed IL-4 from human eosinophils. $J$ Immunol 166: 4813-4817.

Beil WJ, Weller PF, Tzizik DM, Galli SJ, Dvorak AM 1993. Ultrastructural immunogold localization of tumor necrosis factor-alpha to the matrix compartment of eosinophil secondary granules in patients with idiopathic hypereosinophilic syndrome. J Histochem Cytochem 41: 1611-1615.

Bjerke T, Gaustadnes M, Nielsen S, Nielsen LP, Schiotz PO, Rudiger N, Reimert CM, Dahl R, Christensen I, Poulsen LK 1996. Human blood eosinophils produce and secrete interleukin 4. Respir Med 90:271-277.

Bozza PT, Yu W, Cassara J, Weller PF 1998. Pathways for eosinophil lipid body induction: differing signal transduction in cells from normal and hypereosinophilic subjects. J Leukoc Biol 64: 563-569.

Bozza PT, Yu W, Penrose JF, Morgan ES, Dvorak AM, Weller PF 1997. Eosinophil lipid bodies: specific, inducible intracellular sites for enhanced eicosanoid formation. J Exp Med 186: 909-920.

Brasaemle DL, Dolios G, Shapiro L, Wang R 2004. Proteomic analysis of proteins associated with lipid droplets of basal and lipolytically-stimulated 3T3-L1 adipocytes. J Biol Chem.

Braun RK, Franchini M, Erard F, Rihs S, De Vries IJ, Blaser K, Hansel TT, Walker C 1993. Human peripheral blood eosinophils produce and release interleukin- 8 on stimulation with calcium ionophore. Eur J Immunol 23: 956-960.

Christie PE, Henderson Jr WR 2002. Lipid inflammatory mediators: leukotrienes, prostaglandins, platelet-activating factor. Clin Allergy Immunol 16: 233-254.

Crivellato E, Candussio L, Mallardi F, Ribatti D 2002. Recombinant human alpha-2a interferon promotes an atypical process of mast cell secretion with ultrastructural features suggestive for piecemeal degranulation. J Anat 201: 507-512.

Davis MD, Brown AC, Blackston RD, Gaughf C, Peterson EA, Gleich GJ, Leiferman KM 1998. Familial eosinophilic cellulitis, dysmorphic habitus, and mental retardation. $J$ Am Acad Dermatol 38: 919-928.

Desreumaux P, Delaporte E, Colombel JF, Capron M, Cortot A, Janin A 1998. Similar IL-5, IL-3, and GM-CSF syntheses by eosinophils in the jejunal mucosa of patients with celiac disease and dermatitis herpetiformis. Clin Immunol Immunopathol 88: 14-21.

Dubucquoi S, Desreumaux P, Janin A, Klein O, Goldman M, Tavernier J, Capron A, Capron M 1994. Interleukin 5 synthesis by eosinophils: association with granules and immunoglobulin-dependent secretion. J Exp Med 179: 703-708.

Dvorak AM, Ackerman SJ, Furitsu T, Estrella P, Letourneau L, Ishizaka T 1992. Mature eosinophils stimulated to develop in human-cord blood mononuclear cell cultures supplemented with recombinant human interleukin-5. II. Vesicular transport of specific granule matrix peroxidase, a mechanism for effecting piecemeal degranulation. Am J Pathol 140: 795-807.
Dvorak AM, Furitsu T, Letourneau L, Ishizaka T, Ackerman SJ 1991. Mature eosinophils stimulated to develop in human cord blood mononuclear cell cultures supplemented with recombinant human interleukin-5. Part I. Piecemeal degranulation of specific granules and distribution of Charcot-Leyden crystal protein. Am J Pathol 138: 69-82.

Dvorak AM, Morgan ES, Tzizik DM, Weller PF 1994. Prostaglandin endoperoxide synthase (cyclooxygenase): ultrastructural localization to nonmembrane-bound cytoplasmic lipid bodies in human eosinophils and $3 \mathrm{~T} 3$ fibroblasts. Int Arch Allergy Immunol 105: 245-250.

Dvorak AM, Morgan ES, Weller PF 2001. Ultrastructural immunolocalization of basic fibroblast growth factor to lipid bodies and secretory granules in human mast cells. Histochem J 33: 397-402.

Egesten A, Calafat J, Knol EF, Janssen H, Walz TM 1996. Subcellular localization of transforming growth factor-alpha in human eosinophil granulocytes. Blood 87: 39103918.

Erjefalt JS, Greiff L, Andersson M, Matsson E, Petersen H, Linden M, Ansari T, Jeffery PK, Persson CG 1999. Allergen-induced eosinophil cytolysis is a primary mechanism for granule protein release in human upper airways. Am J Respir Crit Care Med 160: 304-312.

Feng D, Flaumenhaft R, Bandeira-Melo C, Weller P, Dvorak A 2001. Ultrastructural localization of vesicle-associated membrane protein(s) to specialized membrane structures in human pericytes, vascular smooth muscle cells, endothelial cells, neutrophils, and eosinophils. J Histochem Cytochem 49: 293-304.

Fujimoto Y, Itabe H, Sakai J, Makita M, Noda J, Mori M, Higashi Y, Kojima S, Takano T 2004. Identification of major proteins in the lipid droplet-enriched fraction isolated from the human hepatocyte cell line HuH7. Biochim Biophys Acta 1644: 47-59.

Fukuda T, Ackerman SJ, Reed CE, Peters MS, Dunnette SL, Gleich GJ 1985. Calcium ionophore A23187 calcium-dependent cytolytic degranulation in human eosinophils. $J$ Immunol 135: 1349-1356.

Gleich GJ, Schroeter AL, Marcoux JP, Sachs MI, O'Connell EJ, Kohler PF 1984. Episodic angioedema associated with eosinophilia. Trans Assoc Am Physicians 97: 25-32.

Grewe M, Czech W, Morita A, Werfel T, Klammer M, Kapp A, Ruzicka T, Schopf E, Krutmann J 1998. Human eosinophils produce biologically active IL-12: implications for control of T cell responses. J Immunol 161: 415-420.

Hartman M, Piliponsky AM, Temkin V, Levi-Schaffer F 2001. Human peripheral blood eosinophils express stem cell factor. Blood 97: 1086-1091.

Heid HW, Moll R, Schwetlick I, Rackwitz HR, Keenan TW 1998. Adipophilin is a specific marker of lipid accumulation in diverse cell types and diseases. Cell Tissue Res 294: 309-321.

Hide I, Bennett JP, Pizzey A, Boonen G, Bar-Sagi D, Gomperts BD, Tatham PE 1993. Degranulation of individual mast cells in response to $\mathrm{Ca} 2+$ and guanine nucleotides: an all-ornone event. J Cell Biol 123: 585-593.

Horiuchi T, Weller PF 1997. Expression of vascular endothelial growth factor by human eosinophils: upregulation by granu- 
locyte macrophage colony-stimulating factor and interleukin-5. Am J Respir Cell Mol Biol 17: 70-77.

King CL, Thyphronitis G, Nutman TB 1990. Enumeration of IgE secreting B cells. A filter spot-ELISA. J Immunol Methods 132: 37-43.

Lacy P, Levi-Schaffer F, Mahmudi-Azer S, Bablitz B, Hagen SC, Velazquez J, Kay AB, Moqbel R 1998. Intracellular localization of interleukin-6 in eosinophils from atopic asthmatics and effects of interferon gamma. Blood 91: 25082516.

Lacy P, Logan MR, Bablitz B, Moqbel R 2001. Fusion protein vesicle-associated membrane protein 2 is implicated in IFNgamma-induced piecemeal degranulation in human eosinophils from atopic individuals. J Allergy Clin Immunol 107: 671-678.

Lacy P, Mahmudi-Azer S, Bablitz B, Hagen SC, Velazquez JR, Man SF, Moqbel R 1999. Rapid mobilization of intracellularly stored RANTES in response to interferon-gamma in human eosinophils. Blood 94: 23-32.

Lamkhioued B, Gounni AS, Aldebert D, Delaporte E, Prin L, Capron A, Capron M 1996. Synthesis of type 1 (IFN gamma) and type 2 (IL-4, IL-5, and IL-10) cytokines by human eosinophils. Ann N Y Acad Sci 796: 203-208.

Levi-Schaffer F, Lacy P, Severs NJ, Newman TM, North J, Gomperts B, Kay AB, Moqbel R 1995. Association of granulocyte-macrophage colony-stimulating factor with the crystalloid granules of human eosinophils. Blood 85: 25792586.

Lim KG, Wan HC, Bozza PT, Resnick MB, Wong DT, Cruikshank WW, Kornfeld H, Center DM, Weller PF 1996. Human eosinophils elaborate the lymphocyte chemoattractants. IL-16 (lymphocyte chemoattractant factor) and RANTES. J Immunol 156: 2566-2570.

Liu P, Ying Y, Zhao Y, Mundy DI, Zhu M, Anderson RG 2004. Chinese hamster ovary K2 cell lipid droplets appear to be metabolic organelles involved in membrane traffic. $J$ Biol Chem 279: 3787-3792.

Logan MR, Odemuyiwa SO, Moqbel R 2003. Understanding exocytosis in immune and inflammatory cells: the molecular basis of mediator secretion. J Allergy Clin Immunol 111: 923-932; quiz 933.

Meerschaert J, Vrtis RF, Shikama Y, Sedgwick JB, Busse WW, Mosher DF 1999. Engagement of alpha4beta7 integrins by monoclonal antibodies or ligands enhances survival of human eosinophils in vitro. J Immunol 163: 6217-6227.

Moller GM, de Jong TA, Overbeek SE, van der Kwast TH, Postma DS, Hoogsteden HC 1996a. Ultrastructural immunogold localization of interleukin 5 to the crystalloid core compartment of eosinophil secondary granules in patients with atopic asthma. J Histochem Cytochem 44: 6769.

Moller GM, de Jong TA, van der Kwast TH, Overbeek SE, Wierenga-Wolf AF, Thepen T, Hoogsteden HC 1996b. Immunolocalization of interleukin-4 in eosinophils in the bronchial mucosa of atopic asthmatics. Am J Respir Cell Mol Biol 14: 439-443.

Moqbel R, Ying S, Barkans J, Newman TM, Kimmitt P, Wakelin M, Taborda-Barata L, Meng Q, Corrigan CJ, Durham SR
1995. Identification of messenger RNA for IL-4 in human eosinophils with granule localization and release of the translated product. J Immunol 155: 4939-4947.

Nakajima T, Yamada H, Iikura M, Miyamasu M, Izumi S, Shida H, Ohta K, Imai T, Yoshie O, Mochizuki M, Schroder JM, Morita Y, Yamamoto K, Hirai K 1998. Intracellular localization and release of eotaxin from normal eosinophils. FEBS Lett 434: 226-230.

Nonaka M, Nonaka R, Woolley K, Adelroth E, Miura K, Okhawara Y, Glibetic M, Nakano K, O’Byrne P, Dolovich J 1995. Distinct immunohistochemical localization of IL-4 in human inflamed airway tissues. IL-4 is localized to eosinophils in vivo and is released by peripheral blood eosinophils. J Immunol 155: 3234-3244.

Ohkawara Y, Lim KG, Xing Z, Glibetic M, Nakano K, Dolovich J, Croitoru K, Weller PF, Jordana M 1996. CD40 expression by human peripheral blood eosinophils. J Clin Invest 97: 1761-1766.

Pacheco P, Bozza FA, Gomes RN, Bozza M, Weller PF, CastroFaria-Neto HC, Bozza PT 2002. Lipopolysaccharide-induced leukocyte lipid body formation in vivo: innate immunity elicited intracellular Loci involved in eicosanoid metabolism. J Immunol 169: 6498-6506.

Rand TH, Cruikshank WW, Center DM, Weller PF 1991. CD4mediated stimulation of human eosinophils: lymphocyte chemoattractant factor and other CD4-binding ligands elicit eosinophil migration. J Exp Med 173: 1521-1528.

Romagnani S 1997. The Th1/Th2 paradigm. Immunol Today 18: 263-266.

Rothenberg ME, Zimmermann N, Mishra A, Brandt E, Birkenberger LA, Hogan SP, Foster PS 1999. Chemokines and chemokine receptors: their role in allergic airway disease. J Clin Immunol 19: 250-265.

Sabin EA, Pearce EJ 1995. Early IL-4 production by non-CD4+ cells at the site of antigen deposition predicts the development of a T helper 2 cell response to Schistosoma mansoni eggs. J Immunol 155: 4844-4853.

Sabin EA, Kopf MA, Pearce EJ 1996. Schistosoma mansoni egg-induced early IL-4 production is dependent upon IL-5 and eosinophils. J Exp Med 184: 1871-1878.

Scepek S, Moqbel R, Lindau M 1994. Compound exocytosis and cumulative degranulation by eosinophils and their role in parasite killing. Parasitol Today 10: 276-278.

Shi HZ, Humbles A, Gerard C, Jin Z, Weller PF 2000. Lymph node trafficking and antigen presentation by endobronchial eosinophils. J Clin Invest 105: 945-953.

Tedla N, Bandeira-Melo C, Tassinari P, Sloane DE, Samplaski M, Cosman D, Borges L, Weller PF, Arm JP 2003. Activation of human eosinophils through leukocyte immunoglobulin-like receptor 7. Proc Natl Acad Sci USA 100: 11741179.

Weiler CR, Kita H, Hukee M, Gleich GJ 1996. Eosinophil viability during immunoglobulin-induced degranulation. $J$ Leukoc Biol 60: 493-501.

Weller PF, Lee CW, Foster DW, Corey EJ, Austen KF, Lewis RA 1983. Generation and metabolism of 5-lipoxygenase pathway leukotrienes by human eosinophils: predominant production of leukotriene C4. Proc Natl Acad Sci USA 80: 7626-7630.

Weller PF, Rand TH, Barrett T, Elovic A, Wong DT, Finberg 
RW 1993. Accessory cell function of human eosinophils. HLA-DR-dependent, MHC-restricted antigen-presentation and IL-1 alpha expression. J Immunol 150: 2554-2562.

Woerly G, Decot V, Loiseau S, Loyens M, Chihara J, Ono N, Capron M 2004. CD28 and secretory immunoglobulin Adependent activation of eosinophils: inhibition of mediator release by the anti-allergic drug, suplatast tosilate. Clin Exp Allergy 34: 1379-1387.

Woerly G, Lacy P, Younes AB, Roger N, Loiseau S, Moqbel R, Capron M 2002. Human eosinophils express and release IL-13 following CD28-dependent activation. J Leukoc Biol 72: 769-779.

Woerly G, Roger N, Loiseau S, Dombrowicz D, Capron A,
Capron M 1999. Expression of CD28 and CD86 by human eosinophils and role in the secretion of type 1 cytokines (interleukin 2 and interferon gamma): inhibition by immunoglobulin a complexes. J Exp Med 190: 487-495.

Ying S, Meng Q, Taborda-Barata L, Corrigan CJ, Barkans J, Assoufi B, Moqbel R, Durham SR, Kay AB 1996. Human eosinophils express messenger RNA encoding RANTES and store and release biologically active RANTES protein. Eur J Immunol 26: 70-76.

Yu W, Bozza PT, Tzizik DM, Gray JP, Cassara J, Dvorak AM, Weller PF. 1998. Co-compartmentalization of MAP kinases and cytosolic phospholipase A2 at cytoplasmic arachidonate-rich lipid bodies. Am J Pathol 152: 759-769. 
